\title{
LysoTracker is a marker of differentiated alveolar type II cells
}

\author{
Joanne L Van der Velden, Ivan Bertoncello and Jonathan L McQualter
}

\begin{abstract}
Background: LysoTracker Green DND-26 is a fluorescent dye that stains acidic compartments in live cells and has been shown to selectively accumulate in lamellar bodies in alveolar type II (AT2) cells in the lung. The aim of this study was to determine whether the accumulation of LysoTracker in lamellar bodies can be used to isolate viable AT2 cells by flow cytometry and track their differentiation in live-cell culture by microscopy.

Methods: Mouse lung cells were sorted on the basis of $C D 45^{\text {neg }} C D 31^{\text {neg }} E p C A M{ }^{\text {pos }} L y$ soTracker ${ }^{\text {pos }}$ expression and characterized by immunostaining for SP-C and cultured in a three-dimensional epithelial colony-forming unit (CFU-Epi) assay. To track AT2 cell differentiation, lung epithelial stem and progenitor cells were cultured in a CFU-Epi assay with LysoTracker-supplemented media.

Results: The purity of sorted AT2 cells as determined by SP-C staining was $97.4 \%$ and viability was $85.3 \%$. LysoTracker ${ }^{\text {pos }}$ AT2 cells generated SP-C $C^{\text {pos }}$ alveolar epithelial cell colonies in culture, and when added to the CFU-Epi culture medium, LysoTracker marked the differentiation of stem/progenitor-derived AT2 cells.

Conclusions: This study describes a novel method for isolating AT2 cells from mouse lungs. The high purity and viability of cells attained by this method, makes them suitable for functional analysis in vitro. The application of LysoTracker to live cell cultures will allow better assessment of the cellular and molecular mechanisms that regulate AT2 cell differentiation.
\end{abstract}

Keywords: Alveolar type II cells, LysoTracker, Lung, Differentiation, Cell culture, Flow Cytometry

\section{Background}

Alveolar type II (AT2) cells are specialized epithelial cells in the lung and comprise the majority of cells in the alveoli. They are responsible for the production and secretion of lung surfactant and can also give rise to alveolar type I (AT1) cells during development [1] and following injury in the adult lung [2].

Given the importance of AT2 cells in surfactant secretion and their role in the maintenance of alveolar homeostasis, reliable methods for their isolation and characterization in vitro are highly desirable. Many strategies have been developed for the isolation of AT2 cells for molecular analysis and functional cell culture studies. The most widely used is a modification of a method first described by Dobbs and colleagues [3], in which AT2 cells are isolated from disaggregated lung tissue by IgG-panning

\footnotetext{
* Correspondence: jlmcq@unimelb.edu.au

Lung Health Research Centre, Department of Pharmacology and

Therapeutics, University of Melbourne, Melbourne, Victoria, Australia
}

and immunomagnetic leukocyte depletion. Recently, a number of investigators have developed protocols to enrich AT2 cells using flow cytometry on the basis of negative antibody-labeling $[4,5]$. While high cell purities of between 90 to $95 \%$ have been achieved using panning and flow cytometry techniques [5-7], these isolation methods rely on negative-selection and there is considerable variability in the yield and purity reported between groups. Recent studies have identified CD74 as a marker for positive selection [8]. However, the relatively low expression of this marker does not allow the complete resolution of this population from other epithelial types.

Here, we report a novel method for isolating AT2 cells on the basis of positive LysoTracker Green DND-26 staining. LysoTracker is a fluorescent dye that stains acidic compartments in live cells. It has been previously shown to selectively label lamellar bodies in cultured

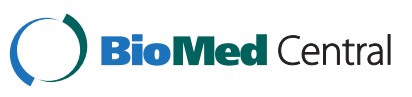

(c) 2013 Van der Velden et al.; licensee BioMed Central Ltd. This is an open access article distributed under the terms of the Creative Commons Attribution License (http://creativecommons.org/licenses/by/2.0), which permits unrestricted use, distribution, and reproduction in any medium, provided the original work is properly cited. 
mouse and rat AT2 cells $[9,10]$. In the present study we show that viable primary AT2 cells can be isolated to high purity on the basis of LysoTracker staining and that LysoTracker is a useful marker of AT2 cell differentiation in vitro.

\section{Methods}

Mice

Female C57Bl/6 mice (6-9 weeks age), were maintained in compliance with the Australian Code of Practice for the Care and Use of Animals for Scientific Purposes and had free access to food and water. Experiments were approved by the Animal Ethics Committee of the University of Melbourne.

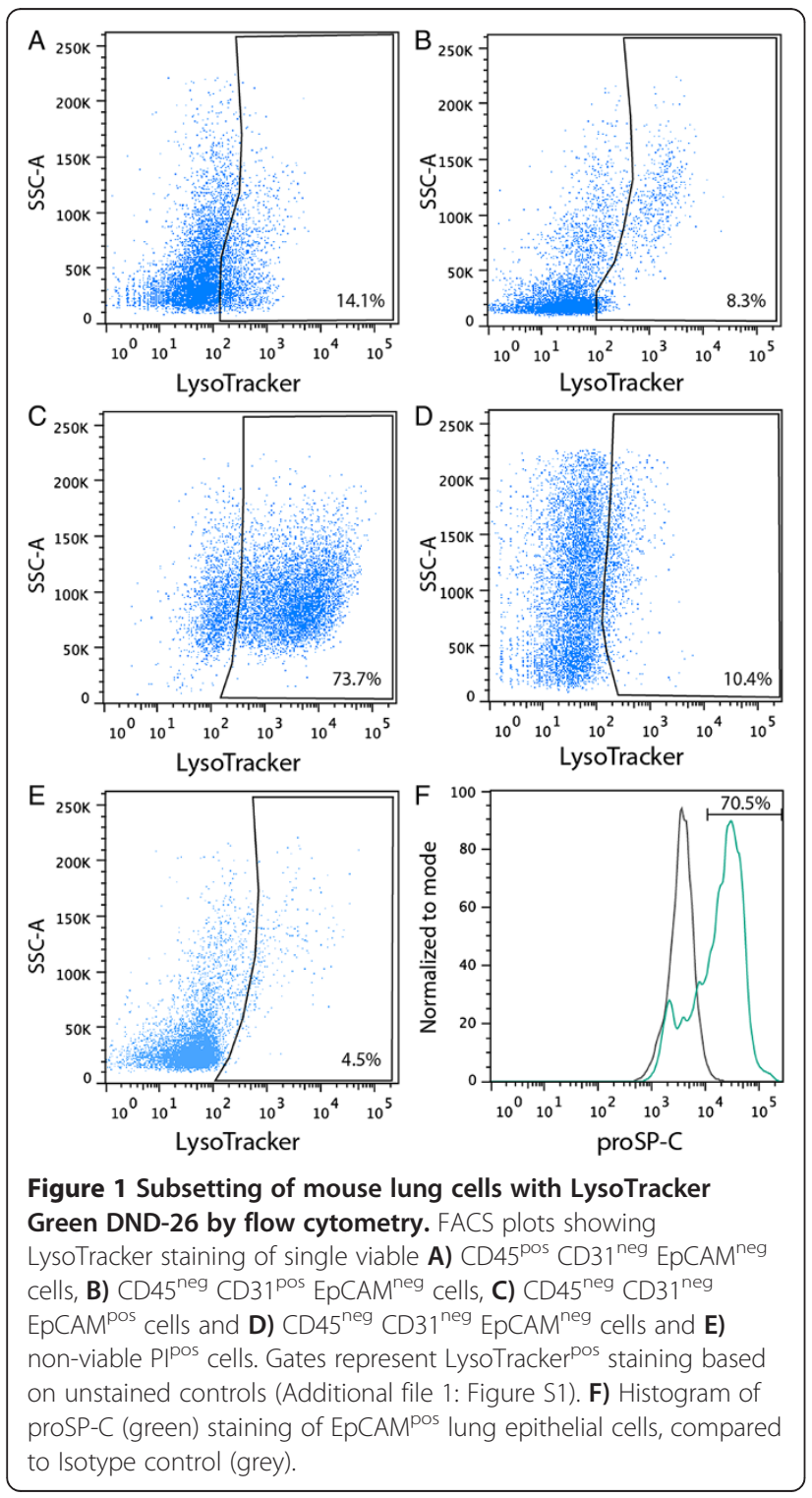

\section{Lung cell preparations and flow cytometry}

Single cell suspensions of lung cells were prepared as previously described [11] with minor modifications. Lungs were minced with a razor blade and incubated with Liberase (1 Wuncsh; Roche) in Hank's buffered saline solution (HBSS; Invitrogen) in a volume of $4 \mathrm{~mL} / \mathrm{lung}$ for $45 \mathrm{~min}$ at $37^{\circ} \mathrm{C}$ in a shaking incubator. Cells were then washed with HBSS plus $2 \%$ fetal bovine serum (FBS; Invitrogen) and resuspended in a red blood cell lysis buffer $\left(10 \mathrm{mM} \mathrm{KHCO}, 150 \mathrm{mM} \mathrm{NH}_{4} \mathrm{Cl}, 0.1 \mathrm{mM}\right.$ EDTA- $\mathrm{Na}_{2}, \mathrm{pH}$ 7.4) for $90 \mathrm{sec}$ at room temperature. Cells were filtered through a $40 \mu \mathrm{m}$ nylon net strainer, washed and resuspended in Dulbecco's Modified Eagle's Medium/F12 (DMEM/F12; Invitrogen) containing LysoTracker Green DND-26 (Invitrogen) at $37^{\circ} \mathrm{C}$ for 45 mins. Cells were washed and resuspended in a cocktail of fluorescein-conjugated antibodies including rat anti-mouse CD45, CD31 and EpCAM (Biolegend) and incubated on ice for 20 mins. Labeled cells were washed in HBSS plus $2 \%$ FBS and resuspended in $1 \mu \mathrm{g} / \mathrm{mL}$ propidium iodide (PI; Invitrogen) for flow cytometry. Viability was determined by staining unfixed cells with propidium iodine (PI), which is an intercalating agent that is unable to permeate live cells but can penetrate the porous cell membranes of dying or dead cells. Doublets were excluded by forward/side scatter-height vs. forward/side scatter-width gating. Sorting was performed with a BD FACS Aria III Cell Sorter using a $100 \mu \mathrm{m}$ nozzle at 30 psi. Analysis was performed with a BD LSR Fortessa analyzer. Data was analyzed using FlowJo vX (Tree Star) software. Setting of LysoTracker ${ }^{\text {pos }}$ gates was based on full staining minus LysoTracker controls (Additional file 1: Figure S1).

Viable AT2 cells were sorted on the basis of their $\mathrm{PI}^{\text {neg }} \mathrm{CD} 5^{\text {neg }} \mathrm{CD}{ }^{\text {neg }}$ EpCAM $^{\text {pos }}$ LysoTracker $^{\text {pos }}$ staining characteristics, and lung epithelial stem/progenitor cells were isolated on the basis of their $\mathrm{PI}^{\text {neg }} \mathrm{CD} 45^{\text {neg }}$ $\mathrm{CD}_{31}{ }^{\text {neg }} \mathrm{EpCAM}^{\text {pos }} \mathrm{CD} 24^{\text {low }}$ signature profile as previously described $[11,12]$.

\section{Epithelial colony-forming unit (CFU-Epi) assay}

Sorted epithelial cells $\left(5 \times 10^{4}\right.$ AT2 cells/mL or $1 \times 10^{4}$ epithelial progenitor cells $/ \mathrm{mL}$ ) were mixed with $\mathrm{Mlg}$ cells (Murine lung fibroblast cell line; American Type Culture Collection CCL-206) $\left(2 \times 10^{6}\right.$ cells $\left./ \mathrm{mL}\right)$ and resuspended in $25 \mu \mathrm{L}$ of Matrigel pre-diluted $1: 1(\mathrm{v} / \mathrm{v})$ in DMEM/F12 containing 10\% fetal bovine serum (FBS), penicillin, streptomycin, glutamax (PSG; Invitrogen), insulin, transferrin and selenium (ITS; Invitrogen), and 0.0002\% heparin (Stem Cell Technologies). Three replicate $25 \mu \mathrm{L}$ droplets of this cell suspension were deposited on the surface of individual 6-well Transwell filter inserts (Millicell-CM; Millipore) placed in wells containing $1.2 \mathrm{~mL}$ of DMEM/F12 supplemented with $10 \%$ FBS, PSG, ITS and heparin. Airway, alveolar and 
mixed-lineage epithelial colonies were defined by their distinct morphologies as previously described [11].

\section{Immunohistochemistry}

Cytospots of isolated $C D 45^{\text {neg }} C D 31^{\text {neg }} E p C A M^{\text {pos }}$ LysoTracker $^{\text {pos }}$ cells and whole-mount cultures were fixed in $4 \%$ paraformaldehyde and labeled using standard
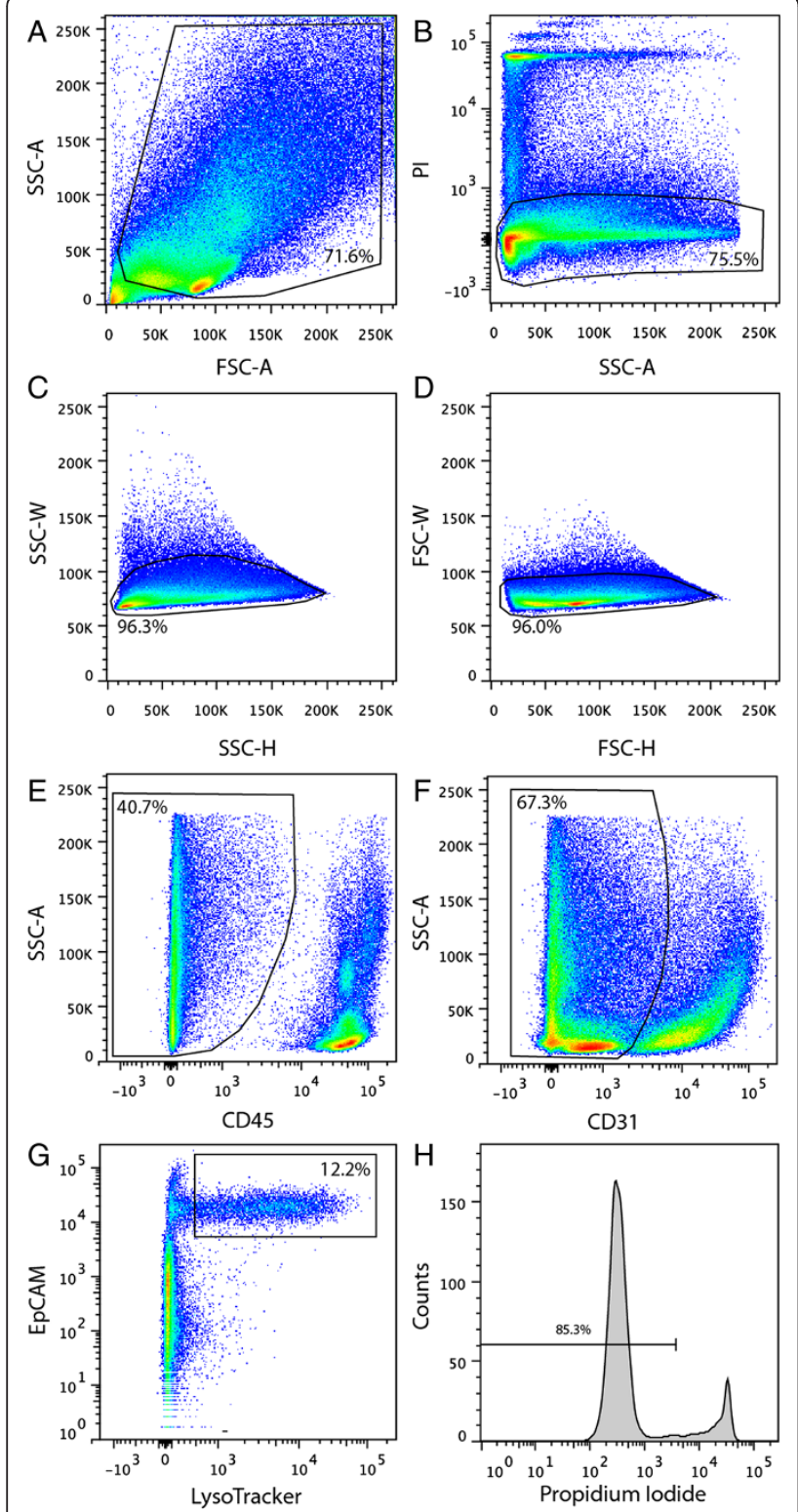

Figure 2 Isolation of LysoTracker ${ }^{\text {pos }}$ alveolar type II cells.

FACS plots showing the sequential gating strategy used to isolate AT2 cells. AT2 cells were gated on the basis of $\mathbf{A}$ ) size (FSC vs. SSC), B) viability $\left(\mathrm{PI}^{\text {neg }}\right)$ and the exclusion of $\mathbf{C}$-D) cell doublets. Viable E) non-haematopoietic cells (CD45 ${ }^{\text {neg }}$ ) and $\mathbf{F}$ ) non-endothelial cells $\left(\mathrm{CD} 31^{\text {neg }}\right)$ were then gated on prior to sorting AT2 cells on the basis of their differential expression of $\mathbf{G}$ ) EpCAM and Lysotracker staining. H) Histogram showing viability analysis (PI) of sorted EpCAM ${ }^{\text {pos }}$ LysoTracker $^{\text {pos }}$ cells at 4 hours post-sort. immunohistochemistry techniques. AT2 cells were labeled with rabbit anti-proSP-C (1/100; Millipore) overnight at $4^{\circ} \mathrm{C}$. Rabbit IgG (Millipore) was used as an isotype control. After washing, cells were incubated with Alexa Fluor-568 conjugated donkey anti-rabbit IgG (1/500; Invitrogen) for 1 hour at room temperature. Nuclei were labeled with 500 nM 4, 6-diamidino-2-phenylindole (DAPI; Invitrogen).
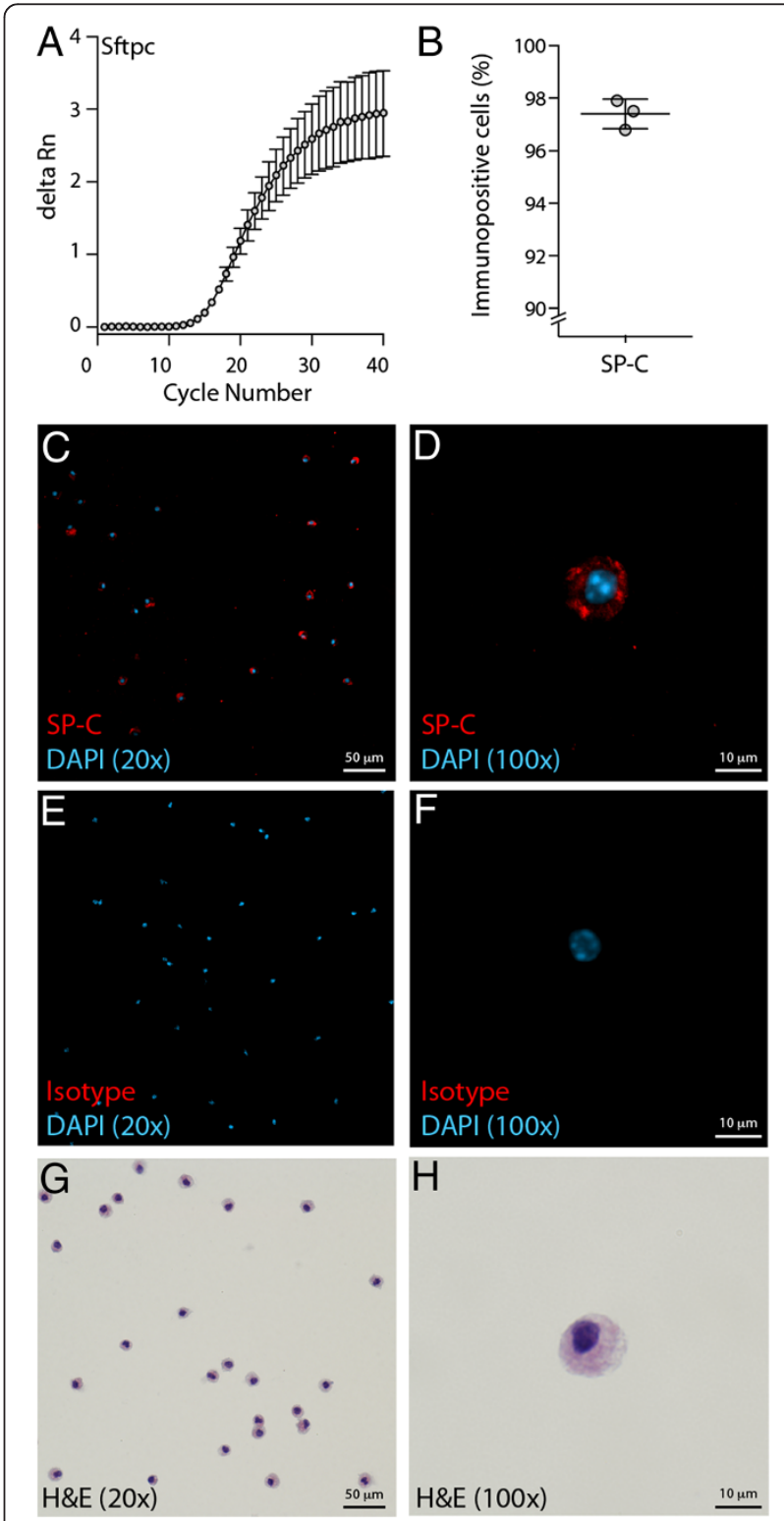

Figure 3 AT2 lineage analysis of primary $\mathrm{PI}^{\text {neg }} \mathrm{CD} 45^{\text {neg }} \mathrm{CD} 31^{\text {neg }}$ EpCAM $^{\text {pos }}$ LysoTracker $^{\text {pos }}$ cells. A) Amplification plot from qRT-PCR of Sftpc expression in LysoTrackerpos AT2 cells. B) Percentage of LysoTracker ${ }^{\text {pos }}$ AT2 cells that were immunopositive for proSP-C (mean $\pm \mathrm{SEM}, \mathrm{n}=3$ independent sorts). Representative images of LysoTracker ${ }^{\text {pos }}$ AT2 cells stained with C-D) proSP-C (plus DAPI), E-F) Isotype control (plus DAPI) and G-H) hematoxylin and eosin (H\&E). 


\section{Statistics}

Unpaired nonparametric t-tests were used to evaluate statistical significance at $\mathrm{p} \leq 0.05$ (GraphPad Prism statistics software, version 6). All quantitative and qualitative analyses are representative of $n \geq 3$ biological repeats for all experiments.

\section{Results and discussion}

Lamellar bodies in AT2 cells are members of a subclass of acidic lysosome-related organelles referred to as secretory lysosomes. The acidic $\mathrm{pH}$ of lysosomes allows for their specific staining with the basic membrane-permeant fluorophore, LysoTracker Green DND-26 (Ex/Em: 504/ $511 \mathrm{~nm}$ ), which selectively accumulates in acidic organelles in live cells. That means that the amount of fluorescence obtained from staining with LysoTracker is directly related to the volume of lysosome-related organelles in a cell. The aim of this study was to use the selective accumulation of LysoTracker in lamellar bodies as a method for subsetting viable AT2 cells by flow cytometry, and tracking their differentiation in live-cell culture by microscopy.

Staining of whole lung cell suspensions with LysoTracker $\left(100 \mathrm{nM}, 30 \mathrm{~min}, 37^{\circ} \mathrm{C}\right)$ resulted in $9.8 \%$ of single lung cells being LysoTracker-positive. When used in combination with lineage specific antibodies,
LysoTracker resolves $14.1 \%$ of viable hematopoietic cells $\left(\mathrm{CD} 45^{\text {pos }} \mathrm{CD} 1^{\text {neg }} \mathrm{EpCAM}^{\text {neg }}\right.$ Figure $\left.1 \mathrm{~A}\right), 8.3 \%$ of viable endothelial cells $\left(C D 45^{\text {neg }} C D 31^{\text {pos }}\right.$ EpCAM $^{\text {neg }}$ Figure $\left.1 B\right)$, $73.7 \%$ of viable epithelial cells $\left(C D 45^{\text {neg }} C D 31^{\text {neg }}\right.$ EpCAM $^{\text {pos }}$ Figure $1 C$ ) and $10.4 \%$ of other viable lineagenegative cells $\left(C D 45^{\text {neg }} C D 31^{\text {neg }}\right.$ EpCAM $^{\text {neg }}$ Figure 1D) in the mouse lung. Of these cell populations, epithelial cells exhibited the highest level of LysoTracker staining. In addition, a small fraction (4.5\%) of dead or dying cells $\left(\mathrm{PI}^{\mathrm{pos}}\right)$ were positive for LysoTracker (Figure 1E). The intensity of LysoTracker staining in epithelial cells is indicative of the labeling of lamellar bodies in AT2 cells. Lamellar bodies are one of the largest lysosomal-related organelles in any cell type and have the capacity to accumulate large amounts of LysoTracker. Although co-localisation of LysoTracker dye and the AT2-specific surfactant protein-C (SP-C) cannot be determined because LysoTracker is non-fixable, the proportion of EpCAM ${ }^{\text {pos }}$ LysoTracker $^{\text {pos }}$ lung epithelial cells (73.1\%) and EpCAM ${ }^{\text {pos }}$ SP-C ${ }^{\text {pos }}$ cells (70.5\%) is comparable (Figure 1F), suggesting that LysoTracker can be used to selectively identify and isolate AT2 epithelial cells by flow cytometry.

Here we also show that, when used in combination with CD45, CD31, EpCAM, and PI, the selective uptake
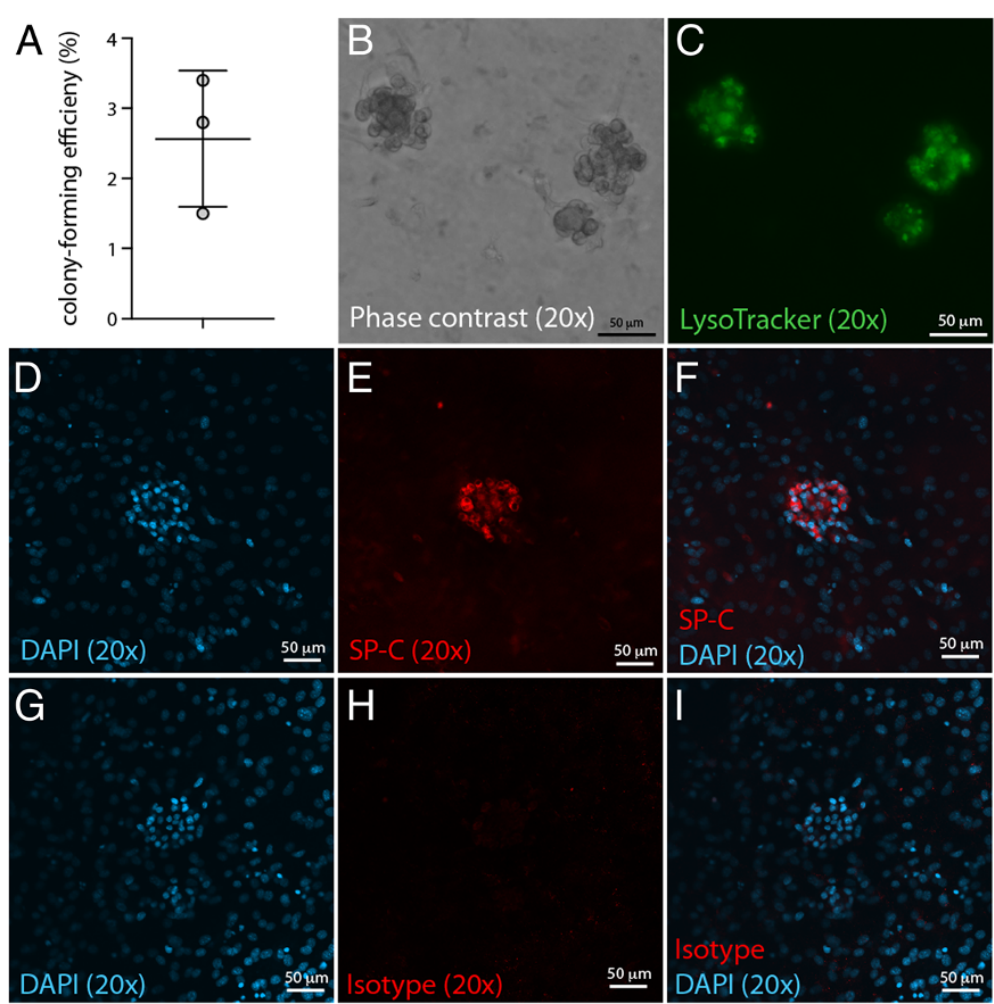

Figure 4 Colony-forming potential of primary LysoTracker ${ }^{\text {pos }}$ AT2 cells. A) Graph showing colony-forming efficiency of LysoTracker ${ }^{\text {pos }}$ AT2 cells cultured in the CFU-Epi assay (mean \pm SEM, $n=3$ ). Representative images of AT2 colonies with B) Phase-contrast C) LysoTracker staining (50 nM for 30 min), D-F) proSP-C staining (DAPI, SP-C and Overlay) and G-I) Isotype controls (DAPI, Isotype and Overlay). 
of Lysotracker resolves a subset of lung epithelial cells which represents $12.2 \%$ of viable $\left(\mathrm{PI}^{\mathrm{neg}}\right)$, non-haematopoietic (CD45neg) and non-endothelial (CD31 ${ }^{\text {neg }}$ ) lung cells (Figure 2). This is consistent with previous studies reporting that AT2 cells comprise approximately 15\% of CD45 ${ }^{\text {neg }} C D 31^{\text {neg }}$ cells in the lung [13]. The viability of CD $45^{\text {neg }} C D 31^{\text {neg }} E p C A M^{\text {pos }}$ LysoTracker ${ }^{\text {pos }}$ cells was assessed at 4 hours post-sorting by staining unfixed

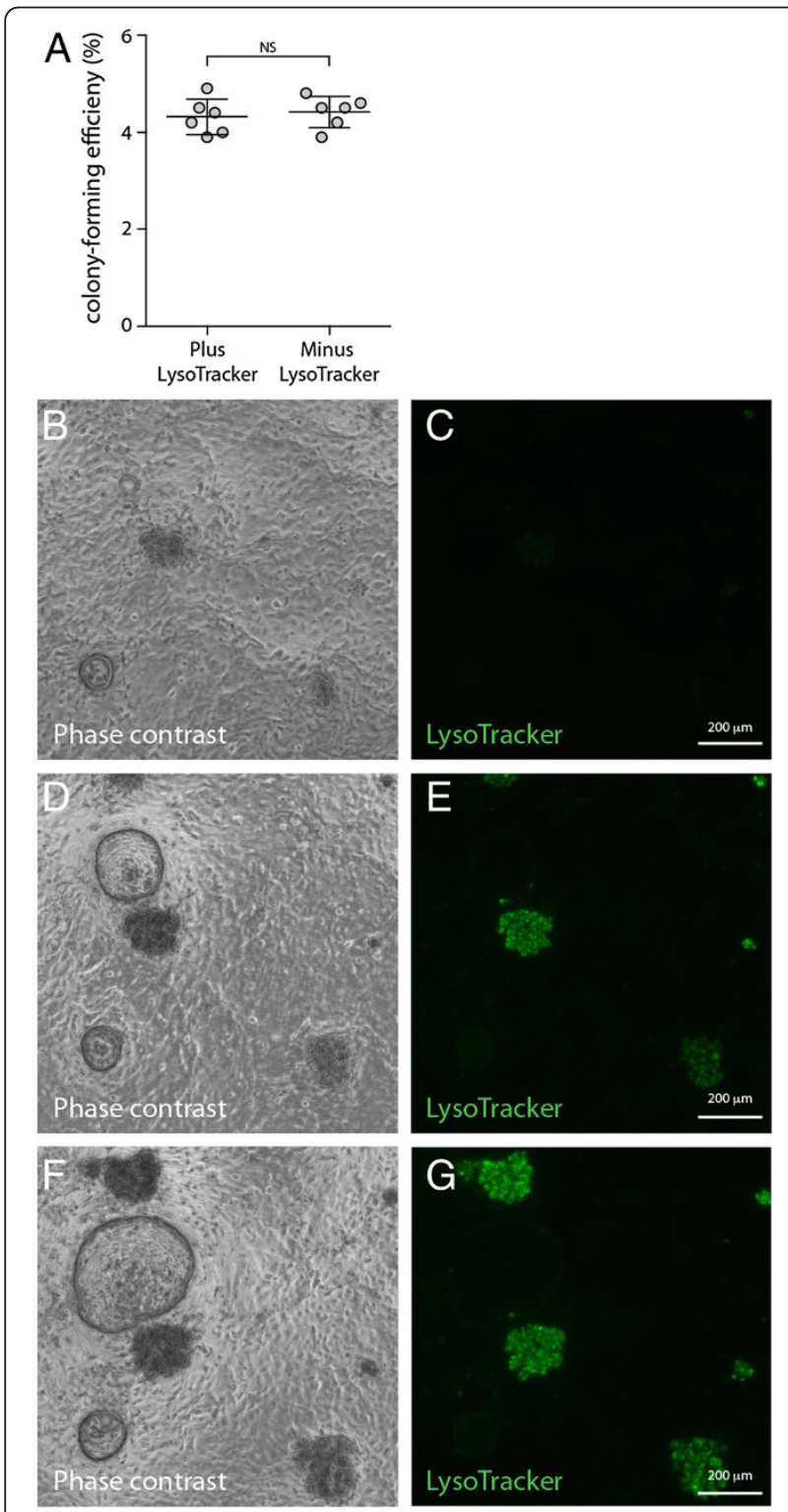

Figure $\mathbf{5}$ Live cell imaging of LysoTracker uptake in differentiated AT2 cells in vitro. A) Graph showing the colonyforming efficiency of epithelial stem and progenitor cells (CD45 ${ }^{\text {neg }}$ $\mathrm{CD}_{31}{ }^{\text {neg }} \mathrm{EpCAM}^{\text {pos }} \mathrm{CD} 104^{\text {pos }} \mathrm{CD} 24^{\text {low }}$ ) cultured in media supplemented with (plus) or without (minus) 50 nM LysoTracker (mean \pm SEM, $n=6$ ). Representative phase contrast and fluorescence images of epithelial stem/progenitor-derived colonies in CFU-Epi cultures grown with LysoTracker-supplemented (50 nM) media after B-C) 9 days D-E) 11 days and $\mathbf{F}-\mathbf{G}) 13$ days of culture. cells with PI. The uptake of PI in only $14.7 \%$ of cells indicates that $85.3 \%$ of cells remained viable after sorting (Figure 2H).

The presence of AT2 cells in the sorted CD45 $5^{\text {neg }}$ CD31 ${ }^{\text {neg }}{ }_{\text {EpCAM }}{ }^{\text {pos }}$ LysoTracker ${ }^{\text {pos }}$ cells was confirmed by qRT-PCR, showing robust expression of Sftpc $(\mathrm{Ct}=15.84 \pm$ 0.18 ), which encodes SP-C (Figure 3A). This was supported by immunofluorescent staining confirming the protein expression of SP-C in $97.4 \pm 0.3 \%$ of the sorted cells (Figure 3B-F). When stained with hematoxylin and eosin, sorted cells exhibited typical cuboidal AT2 cell morphology with large nuclei and cytoplasmic vacuoles (Figure $3 G$ and $H$ ). Together this data demonstrates that LysoTracker enriches for a highly pure population of SP-C ${ }^{\text {pos }}$ AT2 lung epithelial cells.

A number of transgenic mice that express fluorescent proteins under the control of an SP-C promoter have been useful for analyzing AT2 cells in vivo $[8,14]$. However, recent studies have shown that SP-C is also expressed in other bronchiolar cells including bronchioalveolar stem cells [8,15-18]. The advantage of using LysoTracker to identify AT2 cells is that it specifically marks lamellar bodies, which are restricted to functionally differentiated AT2 cells [13].

The use of LysoTracker as an effective label to isolate AT2 cells for subsequent functional analysis, requires that its uptake into lamellar bodies is not toxic and does not alter cell function. Previous studies showing that the uptake and release of LysoTracker by lamellar bodies recapitulates the process of surfactant storage and secretion by exocytosis in cultured AT2 cells $[9,19]$, suggests that LysoTracker does not affect the functional activity of AT2 cells.

Several studies have shown that co-culture of epithelial cells with lung mesenchymal stromal cells in the lung epithelial colony-forming unit assay (CFU-Epi) assay stimulates the proliferation and differentiation of lung epithelial progenitor cells, including AT2 cells $[8,11,14]$. Here we show that AT2 cells sorted on the basis of their $\mathrm{CD}_{4} 5^{\text {neg }} \mathrm{CD} 1^{\text {neg }}$ EpCAM $^{\text {pos }}$ LysoTracker $^{\text {pos }}$ signature profile formed AT2 cell colonies with an incidence of $2.6 \pm 0.56 \%$ in the CFU-Epi assay (Figure 4A). All colonies were positive for SP-C expression and also stained with LysoTracker in culture (Figure 4B-I), thereby confirming their AT2 cell composition. Non-colony-forming AT2 cells also stained positive for SP-C and Lysotracker, suggesting that differentiated non-proliferating AT2 cells also survive in culture long-term (data not shown). The colony-forming efficiency of AT2 cells in this study is comparable to previous studies of clonogenic cells isolated from SP-C reporter mice (2.3\%, [14]) or enriched in the $\mathrm{CD} 31^{\text {neg }} \mathrm{CD} 45^{\text {neg }} C D 74^{\text {pos }}$ cell fraction (2.6\%; [8]). This is in agreement with the emerging concept that only a subset of mature AT2 cells exhibit progenitor cell activity $[14,15]$, and confirms that Lyso Tracker does not affect the colony-forming potential of AT2 cells. 
Having shown that LysoTracker selectively accumulates in AT2 cells, we next assessed whether this dye could be used to track the differentiation of AT2 cells from stem cells in live-cell culture. Recently, we have shown that lung epithelial stem and progenitor cells $\left(\mathrm{CD} 45^{\text {neg }} \mathrm{CD} 31^{\text {neg }} \mathrm{EpCAM}^{\mathrm{pos}} \mathrm{CD} 104^{\text {pos }} \mathrm{CD} 24^{\text {low }}\right)$ form colonies of differentiated airway, alveolar or mixed lineage epithelial cells in our CFU-Epi assay which can be identified by their distinct morphologies $[11,12]$. Importantly, in this study we show that the addition of $50 \mathrm{nM}$ LysoTracker to CFUEpi culture medium did not affect the growth of epithelial stem and progenitor cell colonies $(4.32 \pm 0.15 \%)$, compared to controls ( $4.42 \pm 0.13 \%$; Figure $5 \mathrm{~A})$. This observation further strengthens our assessment that LysoTracker is non-toxic and demonstrates the potential of LysoTrackersupplemented media for tracking the real-time differentiation of AT2 cells in culture. Figure 5 shows that LysoTracker was selectively taken up by alveolar and mixed lineage epithelial colonies, but not airway colonies or early undifferentiated colonies (Figure 5B-G). Although colocalisation of LysoTracker with differentiated lung epithelial markers could not be demonstrated immunohistochemically because LysoTracker is not fixable, we have previously confirmed the presence of AT2 cells in alveolar and mixed lineage colonies and their absence in airway colonies [11]. Therefore positive LysoTracker staining in differentiated alveolar and mixed lineage colonies suggests that the incorporation of LysoTracker marks the differentiation of AT2 cells in culture, while the absence of LysoTracker staining in colonies of airway and undifferentiated epithelial cells confirms that LysoTracker is not incorporated at detectable levels in non-AT2 epithelial cells.

\section{Conclusions}

This study describes a novel and specific method for isolating AT2 cells from mouse lungs by flow cytometry. Compared to current protocols for isolation of AT2 cells, isolating cells on the basis of LysoTracker staining is quicker and results in very high cell purity and viability. This makes it suitable for isolating cells for functional studies in vitro. This study has also identified LysoTracker as a useful tool for tracking AT2 cell differentiation in live-cell culture by microscopy. Using this method, we have shown supporting evidence that a subset of mature, differentiated LysoTracker ${ }^{\text {pos }}$ AT2 cells exhibit progenitor cell activity with the capacity for self-renewal in vitro.

\section{Additional file}

Additional file 1: Figure S1. Subsetting of mouse lung cells without LysoTracker staining. FACS plots showing LysoTracker unstained controls of single viable A) $C D 45^{\text {pos }} C D 31^{\text {neg }}$ EpCAM ${ }^{\text {neg }}$ cells, B) $C D 45^{\text {neg }} C D 31^{\text {pos }}$

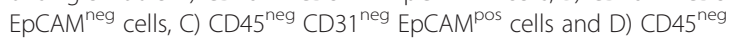
$\mathrm{CD}{ }^{\text {neg }} \mathrm{EpCAM}^{\text {neg }}$ cells and E) non-viable Plpos cells.

\section{Abbreviations}

AT1: Alveolar type 1; AT2: Alveolar type II; CFU-Epi: Epithelial colony-forming unit assay; DMEM: Dulbecco's modified eagle's medium; EpiSPC: Epithelial stem and progenitor cell; FBS: Fetal bovine serum; HBSS: Hank's buffered saline solution; ITS: Insulin, transferrin and selenium; PI: Propidium iodide; PSG: Penicillin, streptomycin, glutamax; SP-C: Surfactant protein-C.

\section{Competing interests}

The authors declare that they have no competing interests.

\section{Authors' contributions}

$J V$ participated in design of all experiments, performed data acquisition and analysis and drafted the manuscript. IB contributed to data analysis and helped write the manuscript. JM conceived of the study, lead the design and coordination of the experimental plan, participated in data acquisition, performed data analysis and helped write the manuscript. All authors read and approved the final manuscript.

\section{Acknowledgments}

This study was supported by a National Health and Medical Research Council (NHMRC) of Australia project grant No. 1009374. JV and JLM were supported by University of Melbourne Early Career Researcher Grants.

Received: 27 August 2013 Accepted: 6 November 2013

Published: 11 November 2013

\section{References}

1. Adamson IY, Bowden DH: Derivation of type 1 epithelium from type 2 cells in the developing rat lung. Lab Invest 1975, 32:736-745.

2. Evans MJ, Cabral LJ, Stephens RJ, Freeman G: Transformation of alveolar type 2 cells to type 1 cells following exposure to NO2. Exp Mol Pathol 1975, 22:142-150.

3. Dobbs LG, Gonzalez R, Williams MC: An improved method for isolating type II cells in high yield and purity. Am Rev Respir Dis 1986, 134:141-145.

4. Fujino N, Kubo H, Ota C, Suzuki T, Suzuki S, Yamada M, Takahashi T, He M, Suzuki T, Kondo T, Yamaya M: A novel method for isolating individual cellular components from the adult human distal lung. Am J Respir Cell Mol Biol 2012, 46:422-430.

5. Gereke M, Autengruber A, Grobe L, Jeron A, Bruder D, Stegemann-Koniszewski S: Flow cytometric isolation of primary murine type II alveolar epithelial cells for functional and molecular studies. J Vis Exp 2012, 70:e4322.

6. Abraham V, Chou ML, DeBolt KM, Koval M: Phenotypic control of gap junctional communication by cultured alveolar epithelial cells. Am J Physiol 1999, 276:L825-L834

7. Chen J, Chen Z, Narasaraju T, Jin N, Liu L: Isolation of highly pure alveolar epithelial type I and type II cells from rat lungs. Lab Invest 2004, 84:727-735

8. Lee JH, Kim J, Gludish D, Roach RR, Saunders AH, Barrios J, Woo AJ, Chen H, Conner DA, Fujiwara Y, et al: SPC H2B-GFP mice reveal heterogeneity of surfactant protein C-expressing lung cells. Am J Respir Cell Mol Biol 2012, 48(3):288-298.

9. Haller T, Ortmayr J, Friedrich F, Volkl H, Dietl P: Dynamics of surfactant release in alveolar type II cells. Proc Natl Acad Sci U S A 1998, 95:1579-1584.

10. Jennings $P$, Bertocchi $C$, Frick M, Haller T, Pfaller W, Dietl P: Ca2+ induced surfactant secretion in alveolar type II cultures isolated from the $\mathrm{H}-2 \mathrm{~Kb}$ tsA58 transgenic mouse. Cell Physiol Biochem 2005, 15:159-166.

11. McQualter JL, Yuen K, Williams B, Bertoncello I: Evidence of an epithelial stem/progenitor cell hierarchy in the adult mouse lung. Proc Natl Acad Sci U S A 2010, 107:1414-1419.

12. Bertoncello I, McQualter J: Isolation and clonal assay of adult lung epithelial stem/progenitor cells. Curr Protoc Stem Cell Biol 2011. Chapter 2:Unit 2G 1 .

13. Dobbs LG: Isolation and culture of alveolar type II cells. Am J Physiol 1990, 258:L134-147.

14. Barkauskas CE, Cronce MJ, Rackley CR, Bowie EJ, Keene DR, Stripp BR, Randell SH, Noble PW, Hogan BL: Type 2 alveolar cells are stem cells in adult lung. J Clin Invest 2013, 123:3025-3036.

15. Chapman HA, Li X, Alexander JP, Brumwell A, Lorizio W, Tan K, Sonnenberg A Wei Y, Vu TH: Integrin alpha6beta4 identifies an adult distal lung epithelial population with regenerative potential in mice. J Clin Invest 2011, 121:2855-2862. 
16. Kim CF, Jackson EL, Woolfenden AE, Lawrence S, Babar I, Vogel S, Crowley D, Bronson RT, Jacks T: Identification of bronchioalveolar stem cells in normal lung and lung cancer. Cell 2005, 121:823-835

17. Roper JM, Staversky RJ, Finkelstein JN, Keng PC, O'Reilly MA: Identification and isolation of mouse type II cells on the basis of intrinsic expression of enhanced green fluorescent protein. Am J Physiol Lung Cell Mol Physiol 2003, 285:L691-700.

18. Teisanu RM, Chen H, Matsumoto K, McQualter JL, Potts E, Foster WM, Bertoncello I, Stripp BR: Functional analysis of two distinct bronchiolar progenitors during lung injury and repair. Am J Respir Cell Mol Biol 2011, 44:794-803.

19. Ichimura H, Parthasarathi K, Lindert J, Bhattacharya J: Lung surfactant secretion by interalveolar Ca2+ signaling. Am J Physiol Lung Cell Mol Physiol 2006, 291:L596-601.

doi:10.1186/1465-9921-14-123

Cite this article as: Van der Velden et al.: LysoTracker is a marker of differentiated alveolar type II cells. Respiratory Research 2013 14:123.

\section{Submit your next manuscript to BioMed Central and take full advantage of:}

- Convenient online submission

- Thorough peer review

- No space constraints or color figure charges

- Immediate publication on acceptance

- Inclusion in PubMed, CAS, Scopus and Google Scholar

- Research which is freely available for redistribution 